\title{
A Time for Reflection
}

At the conclusion of the first year of producing the journal with the Society's new publishers, S. Karger AG, Basel, it is timely to reflect on achievements as well as ways of improving the bimonthly publication.

Regular readers will have noticed the broader scope of articles which are being published, many of them being concerned with newer immunologic and molecular biological techniques as they relate to the topic of differentiation with respect to both basic and clinical oncology. These areas are, at this time, fast-moving scientific topics. Therefore, it is extremely important for the Journal to provide a means whereby such articles can be published rapidly.

So often at meetings of the Society, divergent views are expressed orally and in discussion. It would seem not inappropriate for alternate opinions to be published and to find their way into the pages of the Journal. Accordingly, it has been decided to commence two new features; namely, a correspondence column as well as the opportunity to publish brief communications of approximately 3-4 pages in length.

Over the past 3 years, with UICC sponsorship and Deutsche Krebshilfe financial support, it has been possible to hold a series

of Workshops devoted to the clinical utility of tumor markers. A wide variety of markers has been examined in relation to numerous tumor systems. As a result of these meetings, a consensus report was published in Tumor Biology [8: 65, 1987]. Associated with this report was a series of overviews by each of the participants at those Workshops, each of the views being related to a different marker and/or particular tumor system. Judging by the reprint requests that the several authors and participants have received, these meetings and the reports seem to have generated a significant degree of interest.

In the consensus report, the Committee invited comments and views which may be different from those it had expressed. In fact, many of the participants have received a wide variety of replies. Some of these replies differ in their interpretation from the overviews expressed by the Committee. Some, indeed, are quite critical of the fact that the Committee did not examine the utility of markers in relation to other methods of diagnosing neoplastic disease. Such views are extremely important in deciding upon optimal methods of using tumor markers in a clinical context. One of the alternate views was recently published by Dr. Bormer and his col2

\section{Editorial}

leagues in the Scandinavian Journal of Laboratory Investigation [47: 301, 1987]. It seems that the opportunity to publish replies would be a useful function for the Journal. Accordingly, the Editors have decided to establish a correspondence column. Such 'Letters to the Editor' will invite comments on articles published in the journal, or articles published in other Journals, which will fall within the aims and scope of Tumor Biology.

With the Journal's scientific interests being extended and incorporating 'cutting-edge' research, it is the Editors' opinion that it should also provide a vehicle for brief communications with 
immediate scientific importance. The Managing Editor, accordingly, is looking for short papers containing novel findings of current relevance, not ex-

ceeding 3-4 pages in length, including the abstract, any tables, figures and references. The methods must be described so as to permit repetition and the results must be adequate to justify any claims. Any topic of relevance to oncodevelopmental biology and medicine is appropriate. Preference may be given to papers dealing with the structural and functional aspects of oncology in relation to differentiation, cell lineage analyses and growth factors.

The Editors hope that these two new sections aimed at extending the scope of the Journal will appeal to all readers interested in the protean aspects of oncology.

Munro Neville, Zurich Hidematsu Hirai, Tokyo 